\title{
GaRCÍA Roca, Javier. La transformación constitucional del Conve- nio Europeo de Derechos Humanos, Editorial Civitas, Madrid, 2019, 217 pp., ISBN 9788413085487.
}

\author{
http://dx.doi.org/10.18543/ed-67(2)-2019pp597-601
}

El sistema regional de protección de los derechos humanos estatuido en torno al Consejo de Europa ha experimentado una transformación sustancial, que ha superado con creces los modestos objetivos de partida. En su reciente obra, el profesor García Roca da cuenta de esta evolución, haciendo una completa exposición acerca de dichas transformaciones a lo largo de seis capítulos.

En el primero de ellos, titulado «Los orígenes y la expansión de la jurisdicción europea», se evocan los orígenes históricos del Consejo de Europa, así como las dudas iniciales surgidas respecto de la naturaleza del Convenio Europeo para la Protección de los Derechos Humanos y las Libertades Fundamentales.

Las dificultades en el establecimiento y asentamiento del sistema no fueron menores: habiendo sido dictada la primera sentencia en 1961, el autor identifica varias fases posteriores en su evolución: una fase durmiente, una segunda fase de consolidación del Tribunal y, finalmente, la convalidación del CEDH como una auténtica carta de derechos individuales. Las reformas procesales han tenido una relevancia destacada para aumentar la operatividad y asegurar el buen funcionamiento del sistema, avecinándose, a juicio del autor, una cuarta fase caracterizada por nuevas modificaciones organizativas para evitar que la ingente cantidad de asuntos que llegan al Tribunal provoquen su colapso.

La importancia del Convenio ha conducido a su consideración por el Tribunal como un instrumento constitucional del orden público europeo, aunque la admisión de su naturaleza cuasi constitucional, como se indica, no resulta pacífica. Algunos Estados siguen mostrándose reticentes, pese a que la tendencia homogeneizadora ha acercado las distintas realidades nacionales. En esta línea, las reivindicaciones de subsidiariedad ante los avances del sistema han conducido a la celebración de nuevas Conferencias de Estados, y en ocasiones se han apreciado pugnas en aras de una autocontención del Tribunal.

Una autocontención también requerida por la ausencia de armonización plena entre los instrumentos normativos europeos en materia de derechos, agravadas por la postura del Tribunal de Justicia de la Unión 
Europea que, a juicio del profesor, «exacerba la autonomía del ordenamiento comunitario y adolece de falta de empatía constitucional», impidiendo el desarrollo de los demás ordenamientos. Esta falta de flexibilidad apreciada, sustentada a su juicio sobre argumentos poco convincentes, obliga al mantenimiento de un sistema binario ante la imposibilidad de la adhesión de la Unión Europea al Convenio.

Los solapamientos entre los sistemas, por tanto, han conducido a la creación de pasarelas e interacciones entre los órganos jurisdiccionales, habiendo resultado importante la deferencia recíproca y el denominado «diálogo entre tribunales», fenómeno respecto del cual el autor ha venido manteniendo unas interesantes tesis desde el año 2012 que aún cuentan con plena virtualidad, y que giran en torno a una concepción poco formalista del diálogo que permite su utilización por los operadores jurídicos de tan diversos ordenamientos. Un diálogo que, como se señala, sirve para reforzar la legitimidad del Tribunal Europeo de Derechos Humanos, de modo que el recurso al mismo se torna implícitamente obligatorio.

El último de los retos señalados en el primero de los capítulos hace referencia a la sobrecarga de asuntos para el TEDH, evidenciándose problemas estructurales en algunos Estados. Es frecuente escuchar la expresión que señala que el sistema puede terminar por «morir de éxito», teniendo en cuenta la amplia legitimación, el acceso directo de las víctimas y el número de Estados miembros del Consejo de Europa, que acogen a 800 millones de personas.
Ante esta circunstancia, el autor reflexiona sobre las dificultades de la dispensación de justicia individual, mostrándose partidario de la constitucionalización de la jurisdicción convencional, con la que ya contribuyen las nuevas opiniones consultivas implementadas con el Protocolo 16 (aún no ratificado por España), que permiten «el examen directo y general de las leyes que interfieren en los derechos, en vez de hacerlo únicamente caso a caso y sentencia a sentencia». Las dudas se plantean en torno a la articulación de las cuestiones de inconstitucionalidad, la cuestión prejudicial ante el TJUE y las opiniones consultivas ante el TEDH.

Por lo que respecta al capítulo segundo, titulado: «De una protección internacional al instrumento constitucional del orden público europeo», hace referencia a la labor pretoriana del Tribunal, que en ocasiones conduce al surgimiento de «mutaciones convencionales». El propio Tribunal ha ido construyendo también obligaciones positivas para los Estados, reforzando la vertiente garantista del sistema, y acogidas gracias a la apertura de las constituciones nacionales y la obligación del respeto de las obligaciones asumidas internacionalmente, en un contexto en el que, a juicio del autor, las teorías escalonadas del Derecho ya no resultan lo suficientemente satisfactorias.

Resultan de interés las evidencias expuestas que nuevamente ponen de manifiesto la tendencia a la constitucionalización del tribunal: de un lado, por la labor de tutela de derechos que tiene encomendada, y de otro por el constante recurso a principios 
empleados tradicionalmente por los tribunales constitucionales, tales como el de proporcionalidad, el de protección efectiva, el democrático, el de legalidad o el test del justo equilibrio entre los intereses públicos y privados.

Una buena parte del capítulo segundo se dedica al «margen de apreciación nacional», analizado con profundidad por García Roca en una obra anterior, pero bien sintetizado en la presente. Este margen, basado en la deferencia respecto de la discrecionalidad de los Estados, conduce a una autolimitación del Tribunal ante la presencia de distintas sensibilidades nacionales de índole religiosa, moral o social. Especificidades nacionales que, como se manifiesta, dificultan la fijación de criterios homogéneos en su aplicación. El autor considera que es un instrumento inevitable, pero que ha de ir acompañado de una motivación. También sería deseable, añade, que se den «razonamientos judiciales más previsibles, que garanticen unas deseables dosis de certeza de las decisiones europeas», pese a las dificultades derivadas de la necesidad de valorar factores diversos, señalándose entre otros la falta de un consenso europeo, la naturaleza del derecho en juego, las distintas sensibilidades nacionales o la importancia de alcanzar un equilibrio entre los intereses generales y los individuales.

Por lo que respecta a la nueva tesis del procedimiento razonable de decisión, el autor considera que no hay que desecharla por completo, pero la calidad democrática en la elaboración de una norma por un Parlamento nacional no garantiza que no se vayan a violar derechos. Calidad democrática no siempre implica, de acuerdo con su postura, un resultado garantista.

En el capítulo tercero, titulado «Del filtro de la comisión al acceso individual y directo de las víctimas y la adopción de medidas cautelares», se recalca la importancia del acceso directo de las víctimas, que existe desde hace poco más de dos décadas, habiendo tenido resultados muy positivos para fortalecer y legitimar a la jurisdicción de Estrasburgo. Un recurso individual que, pese a ser el protagonista, no monopoliza las competencias del Tribunal, que también se extienden, de un modo mucho más tímido, a la resolución de asuntos entre Estados o al ejercicio de una competencia consultiva menos intensa que la del Protocolo 16.

Resulta interesante la referencia a las dificultades planteadas dadas las asimetrías en las regulaciones de los mecanismos de protección: algunos Estados carecen de un recurso de amparo, y otros presentan catálogos nacionales en los que no se da una correspondencia entre los derechos fundamentales y los derechos convencionales. Estos problemas han ido sorteándose satisfactoriamente por el TEDH, aunque una solución óptima pasaría, tal y como se expone en este punto, por la acomodación de las regulaciones internas a los estándares de Estrasburgo.

Por lo que respecta a las medidas cautelares, a las que se dedica la última parte del capítulo, no aparecían contempladas en el Convenio y se establecían a partir de una práctica informal entre la Comisión y los Estados, hasta que el Tribunal optó por 
establecer su obligatoriedad a partir del año 2005, hecho que generó críticas de activismo. En la actualidad, al menos, están recogidas en el Reglamento del Tribunal.

En el capítulo cuarto, titulado: «El crecimiento constante de los derechos protegidos algunos derechos sociales», se hace alusión a la fuerza expansiva de los derechos convencionales, que permiten una adaptación del Catálogo a los requerimientos que el tiempo impone. Por lo que respecta a la aparente separación entre derechos civiles y sociales, estos no son compartimentos estancos y en muchas ocasiones se requieren actividades prestacionales para que los derechos civiles gocen de plena virtualidad. Por este motivo, la férrea separación entre los mismos ya ha comenzado a resquebrajarse, observando el autor una tendencia mayor a la tutela indirecta de los derechos sociales.

En el capítulo quinto, con el título «De las sentencias declarativas al restablecimiento íntegro del derecho. Medidas de reparación», se pone de manifiesto la importancia de los pronunciamientos del TEDH, que han reforzado su obligatoriedad y cuentan con eficacia de cosa interpretada y general. Estas circunstancias podrían acompañar a una progresiva objetivación del amparo europeo, evitándose que la labor del órgano sea equiparada a la de un Tribunal de apelación, concentrándose este en la fijación de estándares y principios que sirvan de guía a los tribunales nacionales.

Con el propósito de orientar a las autoridades nacionales se ha implantado, precisamente, el procedimiento de las sentencias piloto, una vez más vinculadas con la tendencia hacia la constitucionalización, y encaminadas a paliar el exceso de asuntos a los que se ve abocada a conocer, en este caso ante violaciones sistemáticas de derechos por parte de un Estado. Este tipo de sentencias refuerzan, por otro lado, la subsidiariedad, siendo muy positivas para el autor porque evitan que el TEDH descuide la ejecución de sus sentencias y contribuyen con el afianzamiento de la eficacia, obligatoriedad y autoridad de sus pronunciamientos.

Por lo que atañe al resarcimiento de las víctimas, la obra hace alusión a sus distintas posibilidades: un reconocimiento de la violación puede ser, en algunos casos, suficiente. Es frecuente la imposición de sanciones pecuniarias, y el sistema ha ido evolucionando, como se aprecia en este capítulo, hacia una plena restitutio in integrum con la implementación de un elenco variadísimo de medidas atendiendo, como no pudiera ser de otra manera, a las circunstancias particulares del caso. La evolución del sistema se aprecia nuevamente en este sentido, ya que el TEDH ha ido imponiendo medidas cada vez más ambiciosas que han llevado, incluso, a la necesidad de llevar a cabo modificaciones legislativas, jurisprudenciales $y$, en último término, constitucionales por parte de los Estados.

Finalmente, en el capítulo sexto, bajo el título: «Del papel del comité de ministros al seguimiento judicial de la ejecución», se concluye poniendo de manifiesto la existencia de una transformación que ha redundado en una mayor eficacia y transparencia en la ejecución de las sentencias, con la 
que contribuyen también los tribunales nacionales incorporando la doctrina y jurisprudencia de Estrasburgo a sus elementos de juicio. Además, el Tribunal ha comenzado a asumir tareas en aras a la ejecución de las sentencias, complementando la labor del Comité de Ministros.

En definitiva, el sistema se ha ido fortaleciendo progresivamente. El Convenio dista mucho de ser un mero tratado internacional, y el TEDH cuenta con una auctoritas muy marcada que ha ido aumentando progresivamente su legitimidad. Las transformaciones expuestas en la obra conducen al lector a constatar que, efectivamente, se ha producido una progresiva transformación constitucional del Convenio Europeo de Derechos Humanos. Una transformación que ha de ser vista con optimismo ya que, pese a los defectos señalados en la obra relativos a la sobrecarga de asuntos, las resistencias de algunos Estados y las fricciones entre órganos jurisdiccionales se ha ido consolidando, en palabras del autor, un ius commune europeo. Un espacio jurídico de los derechos enriquecido por los Estados, cada vez más garantista y que logrará hacer frente de un modo satisfactorio a los grandes retos que se avecinan.

Juan Álvarez Suárez

Doctorando en Derecho Constitucional Universidad de Oviedo 


\title{
GARCÍA Roca, Javier. La transformación constitucional del Conve- nio Europeo de Derechos Humanos, Editorial Civitas, Madrid, 2019, 217 pp., ISBN 9788413085487.
}

\author{
http://dx.doi.org/10.18543/ed-67(2)-2019pp597-601
}

\section{Copyright}

Estudios de Deusto es una revista de acceso abierto, lo que significa que es de libre acceso en su integridad. Se permite su lectura, la búsqueda, descarga, distribución y reutilización legal en cualquier tipo de soporte sólo para fines no comerciales, sin la previa autorización del editor o el autor, siempre que la obra original sea debidamente citada y cualquier cambio en el original esté claramente indicado

Estudios de Deusto is an Open Access journal which means that it is free for full access, reading, search, download, distribution, and lawful reuse in any medium only for non-commercial purposes, without prior permission from the Publisher or the author; provided the original work is properly cited and any changes to the original are clearly indicated. 